\title{
Mapping Young NEETs Across Europe: Exploring the Institutional Configurations Promoting Youth Disengagement from Education and Employment
}

\author{
Marie-Luise Assmann ${ }^{1} \cdot$ Sven Broschinski ${ }^{1}$ \\ Received: 31 July 2020 /Revised: 6 April 2021 / Accepted: 6 April 2021/ \\ Published online: 11 May 2021 \\ (C) The Author(s) 2021
}

\begin{abstract}
Over the past decade, the number of young people neither in employment, education, or training (NEET) has reached a seriously high level in many European countries. Previous studies have illustrated the heterogeneity of this group and that they differ considerably across Europe. However, the reasons of these cross-country differences have hardly been investigated so far. This study explores how the rates of different NEET subgroups are conditioned by various institutional configurations by applying fuzzy-set Quantitative Comparative Analysis for 26 European countries using aggregated EU Labour Force Survey data from 2018. The analysis reveals that institutional causes of being NEET are as diverse as the group itself. Thus, high levels of young NEETs with care responsibilities are found in countries with a lack of family-related services in conjunction with weak formalised long-term care as it is true in mostly Central Eastern European countries. In contrast, high rates of NEETs with a disability are prevalent mainly in Northern European countries where generous and inefficient disability benefit schemes exist that create false incentives to stay away from the labour market. Finally, high proportions of unemployed and discouraged young NEETs are found in those countries hit hardest by the crisis and with high labour market rigidities, low vocational specificity, and a lack of active labour market policies like in the Southern and some Central Eastern European countries. The results illustrate that young people face very different barriers across Europe and that country-specific measures must be taken to reduce the number of NEETs in Europe.
\end{abstract}

Keywords NEETs, $\cdot$ Youth unemployment, $\cdot$ Economic inactivity, $\cdot$ fsQCA, $\cdot$ Institutions

Marie-Luise Assmann

marie-luise.assmann@uol.de

1 Institute for Social Sciences, University of Oldenburg, Oldenburg, Germany 


\section{Introduction}

In recent years, the number of young people who are disengaged from both the labour market and the education and training system - the so-called NEETs (ILO 2015) - has reached a seriously high level in many European countries. The situation worsened due to the Great Recession, especially in those countries that were hit hardest by the crisis (Caroleo et al. 2020). In this context, young NEETs have increasingly become the focus of political and scientific attention because it is assumed that NEETs are at risk of suffering long-term disadvantages. A loss of human capital or 'scarring effects' (Gangl 2006) often result in repeated unemployment spells and lower earnings prospects (Bell and Blanchflower

2010; Gregg and Tominey 2005; Scarpetta et al. 2010). However, NEET is not just a synonym for unemployed. More than half of all young NEETs across Europe are designated as inactive, i.e. not actively looking for a job or training opportunity (Caroleo et al. 2020). Inactive young people seem to be even more distanced from the labour market as they face certain barriers that hinder them even from actively looking for work or make them unavailable for employment (Eurofound 2017). Most inactive young NEETs are not even registered with an employment office and thus are hard to reach for public authorities (OECD 2016). Accordingly, it may be insufficient to adopt labour-market policy instruments that are typically applied to combat youth unemployment to the NEET group. Consequently, policy- makers searching for appropriate strategies to tackle the problems of young NEETs have to consider the diversity of this group as well as the heterogeneous conditions leading to the NEET status. In order to understand what concrete barriers these young people face it is essential to develop a more detailed picture of the various NEET subgroups. Previous research has revealed the diversity of young NEETs and their very different life situations (Cavalca 2016; Eurofound 2016; Yates and Payne 2006). Eurofound (2016) distinguish the subgroups of short-term and long-term unemployed NEETs, NEETs unavailable due to family responsibilities or due to illness or disability, discouraged NEETs, re-entrants and other inactive NEETs. However, NEETs were mainly treated as a homogeneous group in previous studies that have tried to explain the diverse NEET rates by institutional and macro-structural difference (e.g. Caroleo et al. 2020; Eurofound 2012). Accordingly, little is known so far about which institutions influence the level of young people with a specific NEET status in a country. We presume that insufficient attention has been paid in particular to the role of welfare and family policies in comparison alongside labour market and educational Institutions.

Against this background, this study investigates how the rates of different NEET subgroups are conditioned by the interplay of several institutions, i.e. institutional configurations, in order to explain country differences in terms of the NEET population. Given the complexity of the issue, this study is not exhaustive but rather explorative. It aims to raise the awareness of the diversity of both the NEET group itself as well as the policy solutions needed regarding the (re-)activation of young people to enable further research in this area. The article continues with an appraisal of literature related to the concept of NEET and a description of the individual, structural, and institutional determinants known so far. We then present our explorative research design based on fuzzy set Qualitative Comparative Analysis (fsQCA), which allows examination of the interplay between different institutions instead of a separate 
consideration, identifying necessary and sufficient conditions for high rates of different NEET groups. We then present our results against the background of the existing literature before supplying a conclusion and recommendation for further research.

\section{The NEET Concept and the Distinction of NEET Subgroups}

The NEET indicator became popular in the 1990s because it was expected to give a broader perspective on disengagement and the future vulnerability of young people than the youth unemployment indicator (Bynner and Parsons 2002; Samoilenko and Carter 2015; Stanwick et al. 2017). Nowadays, official statistics count young people as NEETs if they meet the condition of being unemployed or inactive and have not received any formal or non-formal education or training in the previous four weeks (Eurostat 2020; ILO 2015). While the NEET concept was initially used only for the narrowly defined age group of young people between 16 and 18 (Furlong 2006), it was later extended to other age groups leading to an increasing heterogeneity of the NEETgroup. In its current application, NEET may include young people who are not in a vulnerable life situation or inactive at all, such as young people who are NEETs for a short time only or who are involved in other meaningful activities including caring responsibilities. Moreover, the NEET concept has been criticised as it still does not include all young people in vulnerable situations, like young people in insecure or lowpaid employment or short-term training programs (Furlong 2006).

To better appreciate the diversity of the NEET group, Eurofound (2016) proposed the following distinction between different subgroups of NEETs: First, the economically active who are looking for and are available to work (the unemployed) which can be further divided into long-term and short-term unemployed NEETS depending on whether they have been unemployed for more or less than 1 year. Second, the economically inactive who are not actively seeking work and/or are not available to work which can be distinguished based on the reasons for not actively searching for or not being available to work. Following Eurofound (2016), investigating why young people are not looking for work helps to identify the different labour market barriers they face: Are they discouraged because they believe that no work is available to them despite their willingness to work (discouraged NEETs)? Are they not seeking work because an incapacity, illness, or disability renders them unavailable to the labour market (NEETs with a disability)? Or do they have various family responsibilities which require them to look after small children or care for sick or elder relatives (care-giving NEETs)? Another subgroup which broadly fits the NEET concept are those who are awaiting their imminent re-entry into employment, education, or training (re-entrants). Finally, a residual group of inactive young people remains (other NEETs) which may include voluntary NEETs with more individual activities such as travelling, volunteering or informal study and/or those who may rely on the financial support of their families (Robson 2008; Ryan 2001 ) but also youth in more problematic life situations. Regarding the heterogeneity of the NEET group across countries, the study of Eurofound (2016) indicates that the extent and composition of NEETs varies considerably across Europe. However, it lacks for a sound empirical investigation on the causes for these cross-country differences. 


\section{Individual, Structural, and Institutional Determinants of Being NEET}

There is little doubt that the risk of a young person becoming NEET is strongly influenced by several individual characteristics: Lower qualifications; early school leaving; having at least one child or being a single parent; having an illness or disability; living in a remote area or small city; or holding an extra-EU migration status (Carcillo et al. 2015; Caroleo et al. 2020; Contini et al. 2019; Eurofound 2012; de Luca et al. 2020; Mascherini 2019; OECD 2016; Robson 2008; Vancea and Utzet 2018). Family background also seems to play a crucial role, as young people with parents who have experienced unemployment, have a low educational level, are poor, or have been divorced also have a higher risk of being NEET (Bynner and Parsons 2002; Caroleo et al. 2020; OECD 2016; Pemberton 2008). While the individual determinants of being NEET are well documented, there remains a lack of research that focuses on countryspecific contexts as conditions for the diversity of young NEETs. Notable exceptions are Eurofound (2012) and Caroleo et al. (2020). Eurofound (2012) have investigated various factors concerning economic growth as well as labour market and educational institutions. In sum, they found that only high ALMPs and a dual system of vocational training have robust and strong effects on NEET rates. The results of Caroleo et al. (2020) point in a similar direction. They demonstrate that an unfavourable condition of the labour market as well as passive labour market instruments increase the individual NEET risks, while economic growth, active labour market policies and high investments in education seem to reduce the probability of being NEET. Even if both studies found economic growth to reduce NEET, the effect is surprisingly weak (Eurofound 2012). This is in line with Dietrich (2013) who highlighted that youth unemployment rates are much more effected by the business cycle compared to the share of NEETs. This strengthens the argument that NEETs are fundamentally different from the young unemployed as they have a much lower attachment to the labour market (Dietrich 2013). However, previous studies did not account for this heterogeneity when examining institutional factors.

In order to investigate the extent of NEET subgroups across countries, we combine the two strands of literature regarding unemployment as well as inactivity among young people. Two groups of NEETs are neglected in the following: first, the 'reentrants' as they are very close to the labour market and only have NEET status for a very short period; Second, the group of 'other NEETs', which is only a residual category and more like a black box, making it nearly impossible to make assumptions about their institutional preconditions. Therefore, we focus on unemployed, discouraged, care-giving NEETs and NEETs with a disability, which are the main subgroups of NEETS that can be distinguished based on their barriers to work and economic activity and that can be characterized as vulnerable. In the following, we review the existing literature regarding possible determinants for these four groups of NEETs.

\section{Unemployed NEETs}

The rich literature on the school-to-work transition and youth labour market integration reveals that the number of young unemployed people in a country is strongly influenced by general economic development (Bell and Blanchflower 2010; Dietrich 2013). Even years after the peak of the Great Recession, the long-lasting effects of the 
tremendous economic downturns on youth employment are still to be expected (Carcillo et al. 2015). However, in particular in those countries hit hardest by the crisis, youth unemployment is not only a macro structural problem (Eichhorst and Neder 2014). Dietrich and Möller (2016) therefore refer to the significance of country-specific institutions in explaining cross-country differences in youth unemployment. One of the most studied factors associated with youth unemployment is the level of employment protection (e.g. Breen 2005; Brzinsky-Fay 2017; de Lange et al. 2014; Russell and O'Connell 2001; Wolbers 2007). It is essential to distinguish between employment protection for regular and for temporary contracts due to the different ways in which they affect young people (Gebel and Giesecke 2016): Employment protection for regular workers is associated with direct and indirect costs of dismissal, which might dissuade employers from hiring young people due to higher anticipated costs in case of a mismatch (Skedinger 2010). The strictness of the use of temporary contracts, on the other hand, is associated with the creation of job opportunities for labour-marketentrants that otherwise would not exist (Korpi and Levin 2001). However, the empirical evidence on both indicators is still very ambiguous (Noelke 2016).

In addition, there is widespread consensus in the literature that a high degree of vocational specificity or a dual apprenticeship system lower the risk of youth unemployment by strengthening the link between education and the labour market and therefore smoothening the transition from school to work (Bol and van de Werfhorst 2013; Breen 2005; Gangl 2001; Shavit and Müller 2000). Furthermore, active labour market policies may help to reduce youth unemployment as they aim to reintegrate young people into work or education (Russell and O'Connell 2001), e.g. by means of job search assistance, training or subsidised work. Therefore, low expenditures on active labour market policies are associated with high levels of youth unemployment (Marques and Hörisch 2020).

\section{Discouraged NEETs}

Regarding discouraged NEETs, studies investigating the causes of discouragement among young people are very scarce. Earlier research (Flaim 1973; Gray et al. 1992) identified two main types of discouraged workers: those who believe that there are no suitable jobs available and those who think they will fail finding a job due to personal deficiencies (van Ham et al. 2001). For the first group, the general economic situation might be the most relevant factor since an unsuccessful job search increases the probability of withdrawing from the labour force (Schweitzer and Smith 1974). For the second group, activation policies may help to reduce discouragement via job-search assistance, training programmes or coaching. According to Hudson (2017), another relevant reason for discouragement among young people is the expected quality of available work, e.g. the extent of atypical employment and low job security. Therefore, the less strict use of fixed-term contracts combined with high levels of dismissal protection (institutional dualism) might increase the rate of discouraged NEETs. As the focus is on young people, it is important to keep in mind that discouragement due to poor job prospects does not necessarily lead to the status of being a discouraged NEET. Some evidence has been found that, in a situation where they see no prospects in the labour market, they might decide to continue education (Raffe and Willms 1989). However, this requires a well-developed and efficient educational system offering good opportunities for further education. 


\section{Care-Giving NEETs}

Two groups of relevant institutional factors influencing the situation of young caregiving NEETs have been identified. First, the presence and availability of comprehensive childcare as well as the net childcare costs seem to play a crucial role for female inactivity in general or at least for the inactivity of parents (Bambra 2007; Eurofound 2016; Thévenon 2013). Second, family cash benefits can also have a positive influence on female employment under certain circumstances, e.g. by covering the costs of mothers' labour force participation (OECD 2013). This is because the main reason for young women being inactive is the family responsibilities they face, which are mainly caring responsibilities for small children (OECD 2016). In addition to childcare, (long-term) care responsibilities for relatives in need, e.g. sick parents or parents with a disability, are another reason for the inactivity of young people. The structure of the health and care system plays a major role in this context. It is known that tremendous differences between European countries exist regarding the question of where people in need of care are attended and cared for. In contrast to the Scandinavian and continental European countries, where formal care provided by public or private providers plays a central role, care is mainly provided informally by relatives due to shortages of formal care in many Eastern European countries (Spasova et al. 2018). A well-developed health care system and high expenditure on long-term care and incapacity might be strongly linked to the extent of care-giving NEETs.

\section{NEETs with a Disability}

Regarding the incapacity of young people to work due to illness or disabilities, previous research reveals that this is not only dependent on the individual's state of health, but also to a large extent on institutional factors. Young people with an incapacity or disability are often marginalised or excluded from the labour market or belong to special employment categories (OECD 2008). While social protection systems for people with disabilities provide them with income security, they also entail the risk of creating incentives to exit employment and to remain in the benefit system permanently (Dixon and Hyde 2000; OECD 2008; WHO 2011). This might be especially true for young unemployed people with disabilities who might prefer the higher disability benefits with less activity requirements compared to the unemployment benefits they are entitled to, which are often only means-tested or flat-rate benefits (OECD 2016). Nordic countries are particularly known to have very high expenditures on disability benefits and also very high rates of disability benefit recipients with more and more young people successfully applying for that kind of benefits and sometimes remaining on it until retirement (OECD 2008). Another factor influencing the labour market integration of people with disabilities are 'overprotective' labour codes and labour market regulations for workers with a disability, which partly work as an obstacle for employment of people with disabilities, as they can make employers more reluctant to hire people with disabilities (WHO 2011). However, special employment programmes, e.g. as part of active labour market measures, can foster the labour market opportunities of people with disabilities by providing coaching, specialised job training, individuallytailored supervision, or even wage subsidies (WHO 2011). On the other hand, a lack of activation policies might retain them in unconditional benefit schemes. 
The literature review revealed the relevance and impact of numerous institutions on the (in-)activity status of young people. However, only the 'net effects' of single institutions under control of other factors were examined assuming that these institutions can unfold their effects independently of each other. This approach widely neglects the theoretical idea of institutional complementarity (see Hall and Soskice 2001), that is the assumption that no single Institution alone but rather the interplay between each other can explain a specific outcome. Thus, the association between the combined effects of single institutions and the disengagement of young people from education and employment constitutes a crucial research gap. Our main arguments are therefore that an institution does not exert its effect alone, but only in combination with one or more other institutions (assumption of conjunctural causation) and that not only one single path may lead to a specific outcome, but that different combinations of institutions can count as causal alternatives for an outcome (assumption of equifinality).

\section{Research Design}

\section{Method}

To examine the institutional configurations that may lead to differences in the prevalence of young NEETs across Europe, we apply the fuzzy set Qualitative Comparative Analysis (fsQCA) approach (Ragin 2000, 2008a). This approach is well suited for comparative analysis with an intermediate number of cases (between 10 and 50) where standard statistical methods may fail to produce reliable results (Ragin 2000) and it has been used in a variety of studies in the field of comparative sociology and politics in the last quarter century (cf. Marx et al. 2014). QCA was intended as a middle way between case-oriented qualitative and variable-oriented quantitative approaches (Ragin 2008b). It aims to achieve a detailed understanding of cases - understood as configurations of analytically relevant characteristics - by identifying the relation between characteristics defined as conditions (and all their possible combinations) and another characteristic defined as the outcome ${ }^{1}$. Due to the set-theoretic foundation of QCA, the relations between these characteristics are conceptualized as set relations, examining which (combination of) conditions are sufficient or necessary ${ }^{2}$ for an outcome of interest (Schneider and Wagemann 2010). Thus, cases can have varying degrees of membership in different sets, i.e. in the conditions and the outcome. In fuzzy set QCA, the membership score can take any value between 0 (full non-membership) and 1 (full membership), where 0.5 is the point of indifference, i.e. a case is neither in nor out of a set (Ragin 2008a). The process of assigning each case a membership score for each condition and outcome is called 'calibration'. We apply the so-called direct method of calibration (Ragin 2008a) by defining the three anchor points $(0,1$, and 0.5$)$ and the software $f_{s} Q C A 3.0$ (Ragin and Davey 2016) calibrates the remaining values based on a log-shaped function. The anchor points are depicted in Table 1, the fuzzy set scores in

\footnotetext{
${ }^{1}$ In QCA, the term condition is used instead of independent variable and outcome instead of dependent variable to avoid confusing with other data analysis techniques (Schneider and Wagemann 2010).

${ }^{2}$ A condition is sufficient if the outcome is present whenever the condition occurs. A condition is necessary if it always occurs whenever the outcome is present (Schneider and Wagemann 2012).
} 
Table 1 Description of the outcomes and conditions

\begin{tabular}{|c|c|c|c|c|}
\hline Label & Indicator & Model & $\begin{array}{l}\text { C a l i b r a ti o n } \\
\text { (anchor points) }\end{array}$ & Source \\
\hline & NEET subgroups (outcomes) & & & \\
\hline URATE & Unemployed NEET rate (15-29 years old) & 1 & $(1.5,4.2,6.9)$ & $\begin{array}{c}\text { EU-LFS } \\
2018\end{array}$ \\
\hline DRATE & Discouraged NEET rate (15-29 years old) & 2 & $(0,0.37,0.9)$ & $\begin{array}{c}\text { EU-LFS } \\
2018\end{array}$ \\
\hline CRATE & Care-giving NEET rate (15-29 years old) & 3 & $(0.9,2.7,4.4)$ & $\begin{array}{c}\text { EU-LFS } \\
2018\end{array}$ \\
\hline \multirow[t]{2}{*}{ IRATE } & Rate of NEETs with a disability (15-29 years old) & 4 & $(0.8,1.3,1.8)$ & $\begin{array}{c}\text { EU-LFS } \\
2018\end{array}$ \\
\hline & Economic development & & & \\
\hline GDP & $\begin{array}{l}\text { Real GDP growth rate between 2008-2013 } \\
\text { Labour market institutions }\end{array}$ & 1,2 & $(-8,0,6)$ & Eurostat \\
\hline EPL & Employment protection legislation for regular workers & $1,2,4$ & $(2,2.5,2.9)$ & OECD \\
\hline EPT & Employment protection legislation for temporary workers & $1,2,4$ & $(1.5,2.2,2.9)$ & OECD \\
\hline \multirow[t]{2}{*}{ ALMP } & $\begin{array}{l}\text { Expenditures on active labour market policies in } \% \text { of GDP } \\
\text { per } \% \text { unemployment }\end{array}$ & $1,2,4$ & $\begin{array}{l}(0.02,0.08 \\
0.13)\end{array}$ & Eurostat \\
\hline & Educational institutions & & & \\
\hline EXPE & Expenditures on education in \% of GDP & 2 & $(3.8,4.9,5.9)$ & Eurostat \\
\hline \multirow[t]{2}{*}{ VET } & $\begin{array}{l}\text { Work-based learning as part of the curriculum of (post) } \\
\text { secondary education }\end{array}$ & 1 & $\begin{array}{l}(16.4,35.1 \\
53.9)\end{array}$ & Eurostat \\
\hline & Welfare institutions & & & \\
\hline MINC & $\begin{array}{l}\text { Guaranteed minimum income as \% of median disposable } \\
\text { income }\end{array}$ & 4 & $\begin{array}{l}(18.7,34.5 \\
50.3)\end{array}$ & OECD \\
\hline EXPH & Expenditures on health care in \% of GDP & 3 & $(4.9,6.6,8.2)$ & Eurostat \\
\hline EXPD & $\begin{array}{l}\text { Expenditures on disability in \% of GDP } \\
\text { Family institution }\end{array}$ & 3,4 & $(1.1,2,2.9)$ & Eurostat \\
\hline EXFC & Expenditures on families in cash in $\%$ of GDP & 3 & $(1,1.4,1.8)$ & Eurostat \\
\hline EXFK & Expenditures on families in kind in $\%$ of GDP & 3 & $(0.1,0.7,1.3)$ & Eurostat \\
\hline CARE & $\begin{array}{l}\text { Net childcare costs (couple with } 67 \% \text { of avg. wage) as } \% \text { of } \\
\text { average wage }\end{array}$ & 3 & $\begin{array}{l}(2.7,11.2 \\
19.7)\end{array}$ & OECD \\
\hline
\end{tabular}

Table 2 and the raw data matrix in Table A1 in the Online Resource. After calibration, the next step is to generate truth tables, which collect all logically possible combinations of conditions (Ragin 2008b) resulting in a truth table with 2 rows where $\mathrm{k}$ is the number of selected conditions and 2 represents the two states of each condition, i.e. above or below the point of indifference (0.5). Afterwards, all cases are assigned to one of these rows in which they fit best regarding their membership scores. For each row, the outcome value has to be determined with 1 for each configuration that is sufficient ${ }^{3}$

\footnotetext{
${ }^{3}$ Sufficiency is determined by the measure of consistency, which is calculated in fsQCA by summing up the minimum values across the membership scores in the conditions and the outcome divided by the sum of the membership values in the condition across all cases (Schneider and Wagemann 2012). We decided to use a threshold of 0.8 to determine whether a condition is regarded as sufficient for the outcome.
} 


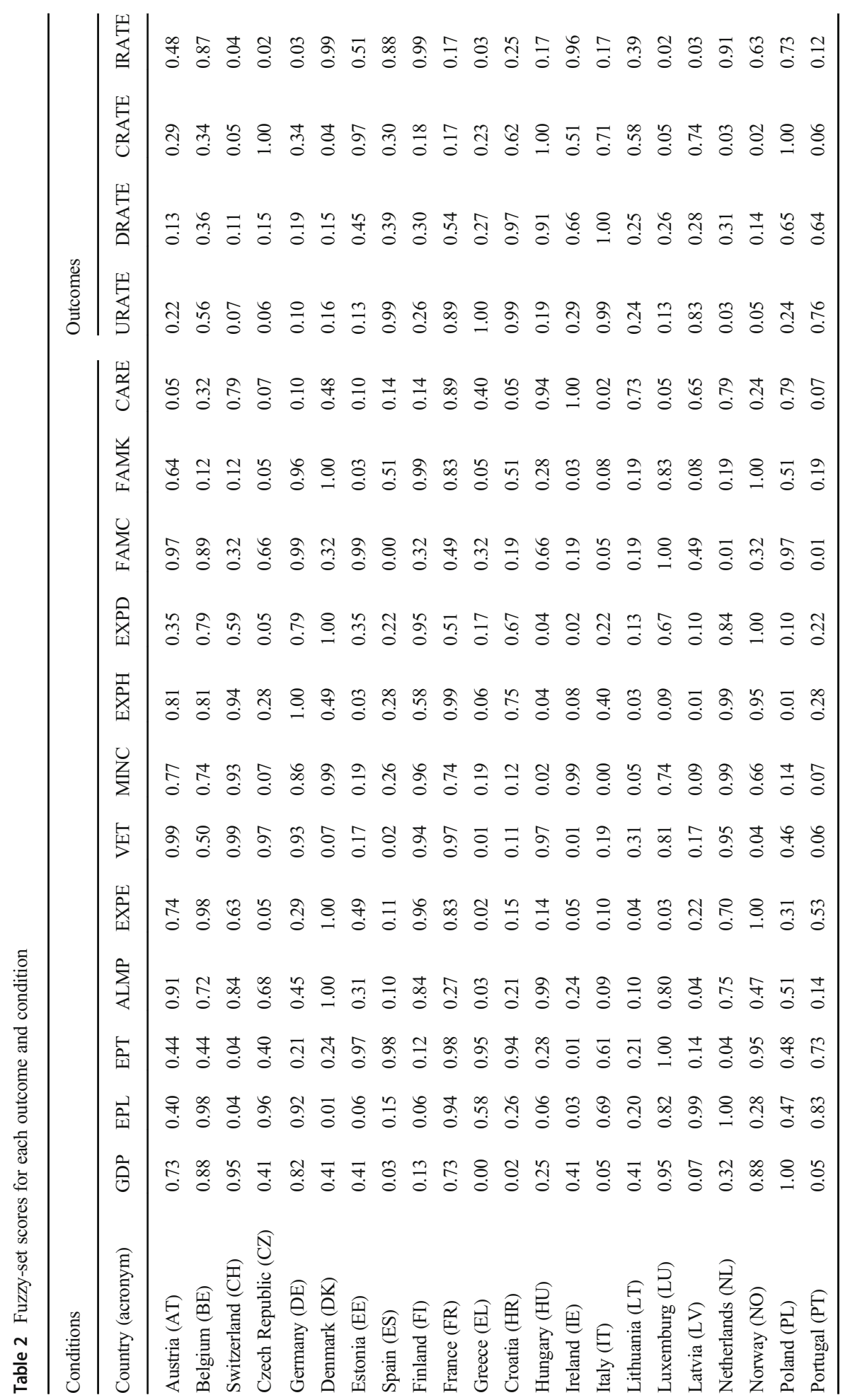




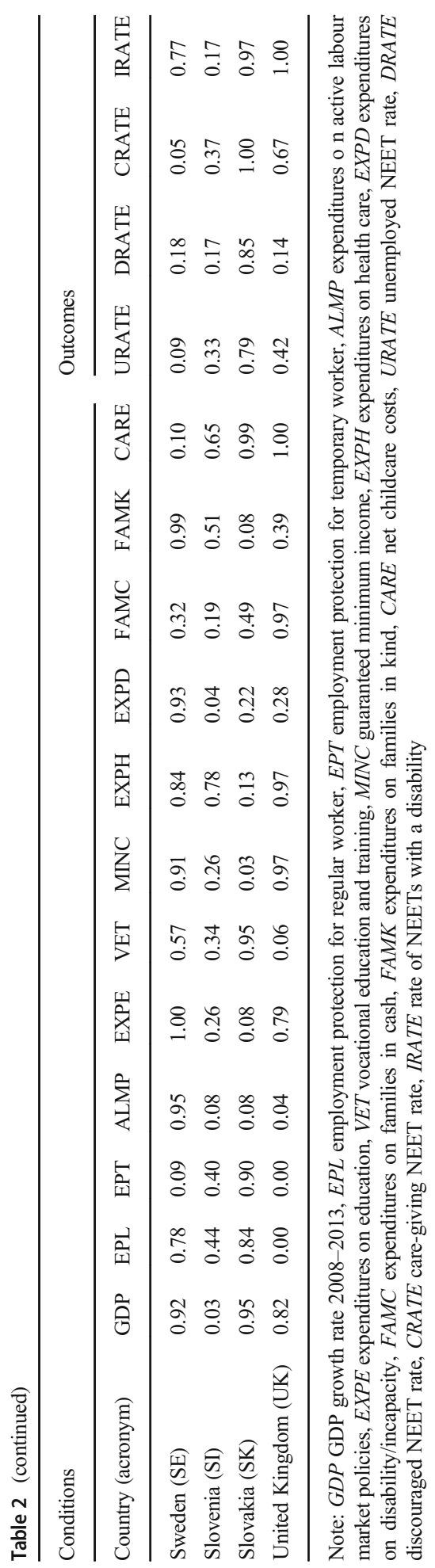


for the outcome and 0 otherwise (Schneider and Wagemann 2012). All truth tables are depicted in Table A4-A7 in the Online Resource. Ina a next step, logically redundant conditions (which are irrelevant to produce the outcome) are eliminated by applying the Quine-McCluskey algorithm in order to create minimal relevant solutions. Since not all potential combinations of conditions are observed empirically (so-called logical remainders), this leads to the problem of limited diversity. The 'Standard Analysis Procedure' as suggested by Ragin (2008b) and applied here provides three strategies on how to handle logical remainders resulting in three different solutions. According to Thiem $(2017,2019)$ and Baumgartner and Thiem $(2017,2020)$, we only report the most parsimonious solution because it is the only solution that can provide causal inference from the data. To assess the quality of a solution, the consistency and coverage measure are applied (Ragin 2008b). Consistency represents the degree of how many cases are covered by a certain solution that is sufficient while coverage measures how much of the outcome is covered by a certain solution and can be interpreted as an indicator of the empirical relevance (Ragin 2006). In this study, we employ fsQCA more as an exploratory tool rather than a hypothesis-testing method to reveal which institutional configurations are necessary or sufficient for high rates of various NEET subgroups.

\section{Outcomes and Conditions}

The outcomes under study are the NEET subgroup rates among young people aged 15 to $29^{4}$. Based on the 2018 EU Labour Force Survey (Eurostat 2017), we distinguish between those who are in work or education and those who are neither in employment nor received any education or training in the previous 4 weeks, i.e. NEETs (ILO 2015). In addition, we subdivide the NEETs following Eurofound (2016) resulting into seven subgroups: Short- and long-term unemployed, re-entrants, NEETs with a disability, care-giving, discouraged, and other NEETs (see the Online Resource for a detailed operation- alisation). To reduce the complexity of the fsQCA, we sum up short- und long-term unemployment as the focus of the analysis will lie more strongly on the hitherto less studied groups of inactive NEETs. Moreover, we neglect the group of the less vulnerable re-entrants and the too diverse group of other NEETs. As conditions, we consider four dimensions of country-specific variables provided by Eurostat and the OECD (detailed descriptions and sources are found in the Online Resource):

1) Labour market institutions such as employment protection legislation for regular worker (EPL) and temporary worker (EPT) as well as expenditures for active labour market policies as a share of GDP per unemployed (ALMP).

2) The educational system, represented by the degree of vocational education and training measured by the share of all 15-to-29-year-olds with (post-) secondary

\footnotetext{
${ }^{4}$ We chose a wider definition of youth considering the 15 to 29 -year-olds to consider that higher education students may still be in the education system at the age of 24 and therefore not yet confronted with the schoolto-work transition. Moreover, we wanted to include older NEETs, where family formation already plays a greater role.
} 
level education where vocational work experience is part of the curriculum (VET) as well as the public expenditures for education as a share of the GDP (EXPE).

3) The welfare system, represented by the guaranteed minimum income relative to the median disposable income (MINC) as well as public expenditures for disability and incapacity (EXPD) and health care (EXPH), both as a share of the GDP.

4) Family policies such as public expenditures for family benefits in cash (FAMC) and in kind (FAMK) as a share of the GDP as well as net childcare costs (CARE) as a share of the average income.

Finally, the general economic situation is measured by the GDP growths between 2008 and 2013 to account for severe economic downturns during the Great Recession which is assumed to still have an impact on the current situation of young people. Due to missing data for some countries, we obtain a total of 26 countries. Following Marx (2006), who argues that a moderate ratio of conditions to cases should be pursued to reduce the number of logical remainders and limit the complexity of the results, only five conditions are included in each model (see Table 1). However, this does not imply that our selection of conditions is exhaustive and that there are no other important factors.

\section{Results and Discussion}

\section{Mapping the NEETs Across Europe}

The NEET rates for 26 European countries are shown in Panel a) of Fig. 1. It is apparent that the degree of young people being NEET is very heterogeneous across Europe. Overall, Southern and Eastern European countries seem to be dominant at the upper half of the distribution, while mainly Continental and Scandinavian countries are found at the lower half. However, the countries differ not only in terms of the level but also in the composition of NEETs. Panel b) shows the relative shares of each subgroup among the total NEET rates. Against this backdrop, we apply a hierarchical cluster analysis ${ }^{5}$ highlighting these cross-country differences (and similarities) in a more sophisticated way. Figure 2 shows five country clusters as well as the absolute (panel a) and relative (panel b) shares of each NEET subgroup. Cluster 1 consists of Germany, Austria, Belgium, the UK, and Ireland as well as Lithuania and Slovenia. It has the second lowest total NEET rate, and short-term unemployed and re-entrants are predominant which speaks for a less consolidated NEET structure in this cluster. Cluster 2, consisting of the Northern European countries plus Luxembourg, the Netherlands, and Switzerland, has the lowest total NEET rate and is characterised by very low unemployment, discouragement, and care-giver rates but high rates of NEETs with a disability - the highest across Europe. Cluster 3 consists of Spain, France, Croatia, Latvia, and Portugal and has the second highest total NEET rate and a very high

\footnotetext{
${ }^{5}$ For the hierarchical cluster analysis, we used the squared Euclidean as measure of distance and the Ward's method for the actual grouping process. The respective dendrogram can be found in the Online Resource (Figure A1). Subsequently, we decided on a number of clusters that were empirically and theoretically most sensible
} 
a) NEET rate $(\%)$

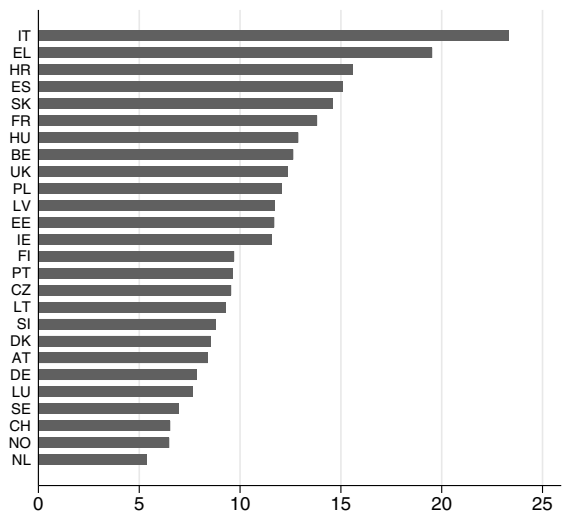

b) Composition of NEETs (\%)

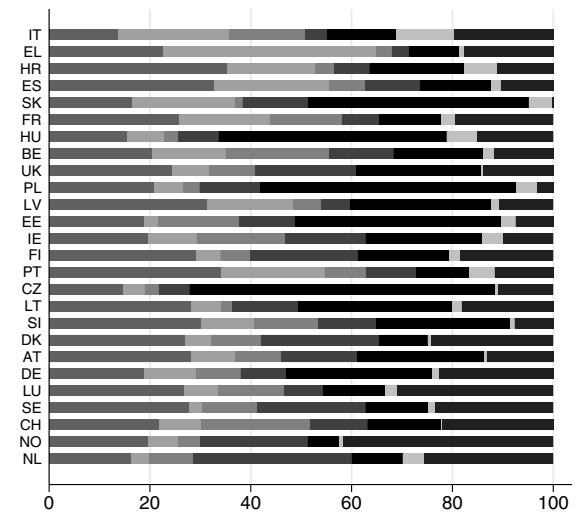

\begin{tabular}{|lll|}
\hline ST-Unemployed & LT-Unemployed & Re-entrants \\
Care-giver & Discouraged & Other
\end{tabular}

Fig. 1 NEET rates and their composition across Europe. Source: EU-LFS 2018, own calculations

proportion of short- and long-term unemployment. Cluster 4 consists of the Czech Republic, Poland, Slovakia, Estonia, and Hungary and has the highest share of care-giving NEETs both in absolute and relative terms. Finally, Cluster 5, which consists of Italy and Greece, has the highest total NEET rate which consists mostly of short- and long-term unemployed NEETs as well as discouraged NEETs. While discouragement is more prevalent in Italy, long-term unemployment plays a major role in Greece. While so far it has been shown that the NEET rates vary considerably between countries, the question remains as to which institutional configurations are associated with these patterns.

\section{Institutional Configurations and Diversity of NEETs}

In the following, we analyse whether some (combinations of) institutions are necessary or sufficient conditions for the presence (or absence) of the four NEET subgroups ${ }^{6}$. The analysis of necessary conditions examines whether a single condition is always present whenever the outcome is present (Ragin 2006). However, the analysis did not reveal any conditions that are necessary for the four outcomes (see Tables A2 and A3 in the Online Resource).

Regarding the analysis of sufficient conditions, Table 3 summarises the configurations that are sufficient for the presence of high and low rates of unemployed NEETs. In Boolean logic, * refers to the logical AND (intersection of sets) while + refers to the logical OR (union of sets). Capitals indicate the presence of a condition/outcome and lower cases its absence. The most parsimonious solution suggests three configurations leading to high youth unemployment: 1) High employment protection for temporary worker and a strong economic downturn (EPT*gdp) or 2) High employment protection for permanent and temporary worker and the lack of activation policies (EPL*EPT*almp) or 3) High

\footnotetext{
${ }^{6}$ An outcome is present if its membership score is above the point of indifference (0.5), and absent if it is below this threshold (see Table 2).
} 
a) Share of all 15-29 years old

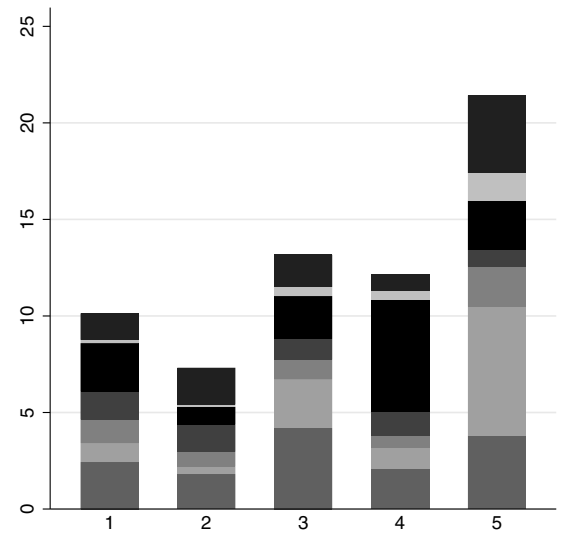

b) Share of all young NEETs

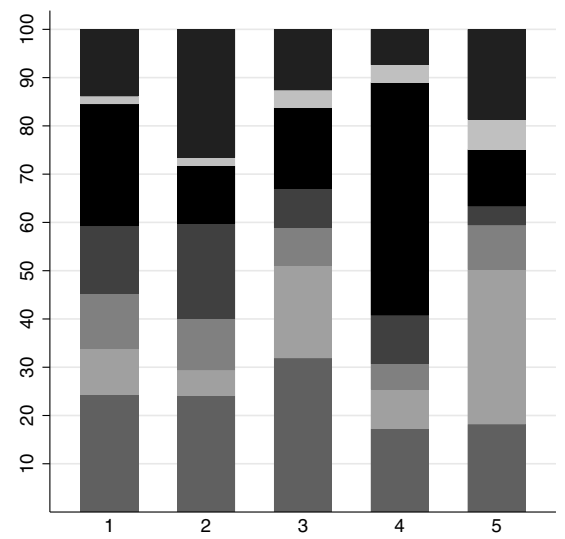

$\begin{array}{lll}\text { ST-Unemployed } & \text { LT-Unemployed } & \text { Re-entrants } \\ \text { Care-giver } & \text { Discouraged } & \text { Other }\end{array}$

Fig. 2 Composition of NEETs by country cluster (in \%). Source: EU-LFS 2018, own calculations. Note: Cluster 1 = DE, AT, BE, UK, IE, LT, SI; Cluster 2= DK, NO, SE, FI, NL, CH, LU; Cluster 3 = ES, PT, FR, HR, LV; Cluster 4 = CZ, PL, SK, EE, HU; Cluster 5 = IT, EL

employment protection for regular worker and the lack of activation policies and vocational education (EPL*almp*vet). It is evident that none of the five single conditions included in the analysis is sufficient alone which corresponds to the assumption of conjunctural causation. Instead, the conditions affect the outcome only in combination. In order to distinguish a configuration as more important than the others, the coverage and consistency scores can be used (Schneider and Wagemann 2012). Configurations with a

Table 3 Analysis of sufficiency for high and low rates of unemployed NEETs

\begin{tabular}{|c|c|c|c|c|c|c|}
\hline \multirow{2}{*}{$\begin{array}{l}\text { Outcome } \\
\text { URATE }\end{array}$} & \multicolumn{2}{|c|}{ Solution } & \multirow{2}{*}{$\begin{array}{l}\begin{array}{l}\text { Raw } \\
\text { coverage }\end{array} \\
0.606\end{array}$} & \multirow{2}{*}{$\begin{array}{l}\begin{array}{l}\text { Unique } \\
\text { coverage }\end{array} \\
0.232\end{array}$} & \multirow{2}{*}{$\begin{array}{l}\text { Consistency } \\
0.841\end{array}$} & \multirow{2}{*}{$\begin{array}{l}\text { Covered cases } \\
\text { ES, EL, HR, PT, IT }\end{array}$} \\
\hline & 1 & $\mathrm{EPT}^{*} \mathrm{gdp}$ & & & & \\
\hline & 2 & EPL*EPT*almp & 0.531 & 0.110 & 0.849 & SK, FR, PT, IT, EL \\
\hline & 3 & EPL*almp*vet & 0.460 & 0.077 & 0.875 & LV, PT, IT, EL \\
\hline & & Solution coverage: & 0.840 & & & \\
\hline & & Solution consistency: & 0.828 & & & \\
\hline \multirow[t]{6}{*}{ urate } & 1 & ALMP & 0.672 & 0.095 & 0.876 & $\begin{array}{l}\text { DK, HU, SE, AT, FI, } \\
\text { CH, LU, NL, CZ, PL }\end{array}$ \\
\hline & 2 & ept*VET & 0.527 & 0.044 & 0.945 & $\begin{array}{l}\text { CH, NL, FI, DE, HU, } \\
\text { CZ, SE, AT }\end{array}$ \\
\hline & 3 & ept *epl & 0.502 & 0.060 & 0.856 & $\begin{array}{l}\text { UK, IE, CH, FI, LT, DK, } \\
\text { HU, SI, AT, PL }\end{array}$ \\
\hline & 4 & epl*GDP & 0.411 & 0.027 & 0.950 & CH, UK, NO, AT, PL \\
\hline & & Solution coverage: & 0.895 & & & \\
\hline & & Solution consistency: & 0.847 & & & \\
\hline
\end{tabular}

Source: Own calculations. Conditions included: EPL, EPT, ALMP, VET, and GDP. Most parsimonious solution 
raw coverage below 0.3 will therefore not be discussed. Accordingly, high hurdles for dismissals and the use of atypical contracts are identified as the dominant factors making employers more reluctant to hire young people especially in the aftermath of an economic downturn exemplified by the Mediterranean countries and Croatia. High overall solution coverage and consistency values are indicating that high rates of unemployed NEETs are very well explained by these three solution paths.

Regarding low rates of unemployed NEETs, four sufficient configurations are identified. High expenditures on active labour market policies, as they can be found in most Nordic and Western European countries, is the most important condition (raw coverage: 0.672 ). In addition, low employment protection for temporary workers is also associated with low youth unemployment rates either combined with low employment protection for regular workers or combined with high levels of vocational education. The overall solution coverage as well as consistency indicates a high explanatory power of this solution. This indicates that a strong vocational orientation of the training systems together with a less restrictive use of temporary contracts makes the transition from school to work much smoother, as the risk of employers hiring a labour market entrant is much lower. Overall, the results of this analysis correspond fairly well to previous studies on the institutional determinants of youth unemployment (e.g. Breen 2005; Brzinsky-Fay 2017; Eichhorst and Neder 2014; Scarpetta et al. 2010). However, our results show that institutions exert their effects mostly in combination with each other and that dif- ferent combinations of institutions can act as functional equivalents, which can lead to the same out- comes.

Table 4 presents the three configurations that are sufficient for high-discouraged NEET rates. The first configuration seems to be the most important regarding coverage and consistency: High rates of discouraged NEETs are therefore linked to the combination of high employment protection for temporary and permanent workers and low expenditures on active labour market policies. This is the case in Slovakia, France, Portugal, and Italy. This is contra the assumptions of Hudson (2017) that deregulated labour markets would result in higher discouragement among young people and against

Table 4 Analysis of sufficiency for high and low rates of discouraged NEETs

\begin{tabular}{|c|c|c|c|c|c|c|}
\hline \multirow{2}{*}{$\begin{array}{l}\text { Outcome } \\
\text { DRATE }\end{array}$} & \multirow{2}{*}{$\begin{array}{l}\text { Solution } \\
1\end{array}$} & \multirow{2}{*}{$\begin{array}{l}\text { Raw coverage } \\
\text { EPL*EPT*almp }\end{array}$} & \multirow{2}{*}{$\begin{array}{l}\text { Unique coverage } \\
0.538\end{array}$} & \multicolumn{2}{|c|}{ Consistency } & \multirow{2}{*}{$\begin{array}{l}\text { Covered cases } \\
\text { SK, FR, PT, IT }\end{array}$} \\
\hline & & & & 0.145 & 0.830 & \\
\hline & 2 & EPT*almp*GDP & 0.389 & 0.016 & 0.830 & $\mathrm{SK}, \mathrm{FR}$ \\
\hline & 3 & epl*ALMP*expe & 0.332 & 0.120 & 0.900 & HU, PL \\
\hline & & Solution coverage: & 0.699 & & & \\
\hline & & Solution consistency: & 0.798 & & & \\
\hline \multirow[t]{7}{*}{ drate } & 1 & EXPE & 0.617 & 0.119 & 0.835 & DK, SE, NO, BE, FI, UK, \\
\hline & & & & & & $\mathrm{AT}, \mathrm{NL}, \mathrm{CH}$ \\
\hline & 2 & ALMP*GDP & 0.489 & 0.013 & 0.926 & $\mathrm{SE}, \mathrm{CH}, \mathrm{LU}, \mathrm{AT}, \mathrm{BE}$ \\
\hline & 3 & ALMP*EPL & 0.395 & 0.018 & 0.910 & LU, SE, NL, BE, CZ \\
\hline & 4 & ept*almp & 0.390 & 0.116 & 0.829 & UK, LV, LT, SI, DE \\
\hline & & Solution coverage: & 0.841 & & & \\
\hline & & Solution consistency: & 0.819 & & & \\
\hline
\end{tabular}

Source: own calculations. Conditions included: EPL, EPT, ALMP, EXPE, GDP. Most parsimonious solution 
the assumptions of the early work regarding discouraged workers (Flaim 1973; Schweitzer and Smith 1974), as a severe economic downturn is not a sufficient condition for high rates of discouraged NEETs. A third configuration indicates that, even when low employment protection and high expenditures on active labour market policies are prevalent, low expenditures on education can lead to high rates of discouraged NEETs, as it is the case for Hungary and Poland.

Low rates of discouraged young NEETs are explained by four configurations. High expenditures on education, which can be found mainly in the Northern European countries, are the single most important condition leading to low discouraged NEET rates. These results indicate that a well-developed education system provides young people with both attractive alternatives to an early labour market entry, which motivates them to stay longer in the education system, and with better overall qualifications and thus improves their labour market chances. In addition, high expenditures for active labour market policies combined with either a high GDP growth or high employment protection for regular workers are also associated with low discouraged NEET rates. Activation policies thus seem to be effective in reducing discouragement among young people by measures of job-search assistance, training programmes or coaching and thus improve job-related skills or finding suitable job opportunities - even with high levels of employment protection. However, a less restrictive use of temporary contracts may also lead to low discouragement despite low expenditures on activation policies, pointing to the role of atypical contracts for the labour market entry of young people.

Regarding high rates of care-giving NEETs (Table 5), it is evident that low expenditures on disability are at least a nearly-necessary condition for high rates of care-giving NEETs because they are part of every configuration. The high rates of care-giving NEETs in Central Eastern Europe as well as in Ireland and the UK are therefore associated with low expenditures on disability and family benefits in kind either in combination with high

Table 5 Analysis of sufficiency for high and low rates of care-giving NEETs

\begin{tabular}{|c|c|c|c|c|c|c|}
\hline \multirow{2}{*}{$\begin{array}{l}\text { Outcome } \\
\text { CRATE }\end{array}$} & \multicolumn{2}{|c|}{ Solution } & \multirow{2}{*}{$\begin{array}{l}\begin{array}{l}\text { Raw } \\
\text { coverage }\end{array} \\
0.527\end{array}$} & \multirow{2}{*}{$\begin{array}{l}\begin{array}{l}\text { Unique } \\
\text { coverage }\end{array} \\
0.117\end{array}$} & \multirow{2}{*}{$\begin{array}{l}\text { Consistency } \\
0.914\end{array}$} & \multirow{2}{*}{$\begin{array}{l}\text { Covered cases } \\
\text { CZ, HU, EE, UK }\end{array}$} \\
\hline & 1 & expd*famk*FAMC & & & & \\
\hline & 2 & expd*famk*CARE & 0.524 & 0.122 & 0.829 & IE, SK, LT, HU, LV, UK \\
\hline & 3 & expd*exph**FAMK & 0.246 & 0.031 & 0.810 & PL \\
\hline & & Solution coverage: & 0.700 & & & \\
\hline & & Solution consistency & 0.796 & & & \\
\hline \multirow[t]{6}{*}{ crate } & 1 & EXPD & 0.668 & 0.157 & 0.869 & DK, NO, FI, SE, NL, BE, \\
\hline & 2 & FAMK $*$ EXPH & 0.507 & 0.031 & 0.919 & $\begin{array}{l}\mathrm{DE}, \mathrm{LU}, \mathrm{CH}, \mathrm{FR} \\
\mathrm{DE}, \mathrm{NO}, \mathrm{SE}, \mathrm{FR}, \mathrm{AT}, \mathrm{FI}, \mathrm{SI}\end{array}$ \\
\hline & 3 & FAMK*care & 0.498 & 0.011 & 0.914 & $\begin{array}{l}\text { DE, SE, LU, NO, AT, FR, } \\
\text { DK, ES }\end{array}$ \\
\hline & 4 & famc*care & 0.473 & 0.117 & 0.800 & PT, ES, EL, NO, SE, DK, FR \\
\hline & & Solution coverage: & 0.896 & & & \\
\hline & & Solution consistency & 0.807 & & & \\
\hline
\end{tabular}

Source: own calculations. Conditions included: EXPH, EXPD, FAMC, FAMK, CARE. Most parsimonious solution 
family cash benefits or with high childcare costs. Regarding low care-giving-NEET-rates, high expenditures on disability benefits seem to be the single most important condition as prevalent mostly in the Nordic countries and the Netherlands. However, three other configurations are leading to the same outcome: high expenditures on families in kind either combined with high expenditures on health care or with low childcare costs, as well as the latter combined with low family cash benefits. With an overall coverage of almost 0.9 and consistency of 0.8 , the solution explains the prevalence of low rates of care-giving NEETs in Europe sufficiently accurate.

The results speak for the fact that a lack of public support for formalised long-term care and childcare leaves important care tasks to be carried out by the family. This particularly affects young women in Central Eastern Europe where the mean age of mothers at first birth as well as the provision of formal care services is the lowest across Europe (Spasova et al. 2018). Especially, the young people caring for their elderly relatives have so far been given too little attention in research. The results support the idea that strong welfare states that defamilise care (Michon 2008) and do not encourage staying at home via high family cash benefits can reduce the incidence of young caregiving NEETs as is the case in many Nordic and Western European countries.

Table 6 shows that two very different configurations are identified as sufficient for high rates of young NEETs with a disability. Either low employment protection for temporary workers combined with high expenditures on active labour market policies and disability or low employment protection for regular workers combined with low expenditures on active labour market policies and high minimum income benefits. While the first configuration is exemplified by Nordic countries, the latter is primary represented by the UK and Ireland. In the Nordic countries, well-developed disability benefits schemes seem to create false incentives and promote economic inactivity among young people or foster the creation of special employment categories with low attachment to the labour market (Dixon and Hyde 2000; OECD 2008; WHO 2011) _ even if investments in active labour market policies are high and restrictions in the use of temporary contracts are low. The findings for Ireland and the UK suggest that

Table 6 Analysis of sufficiency for high and low rates of NEETs with a disability

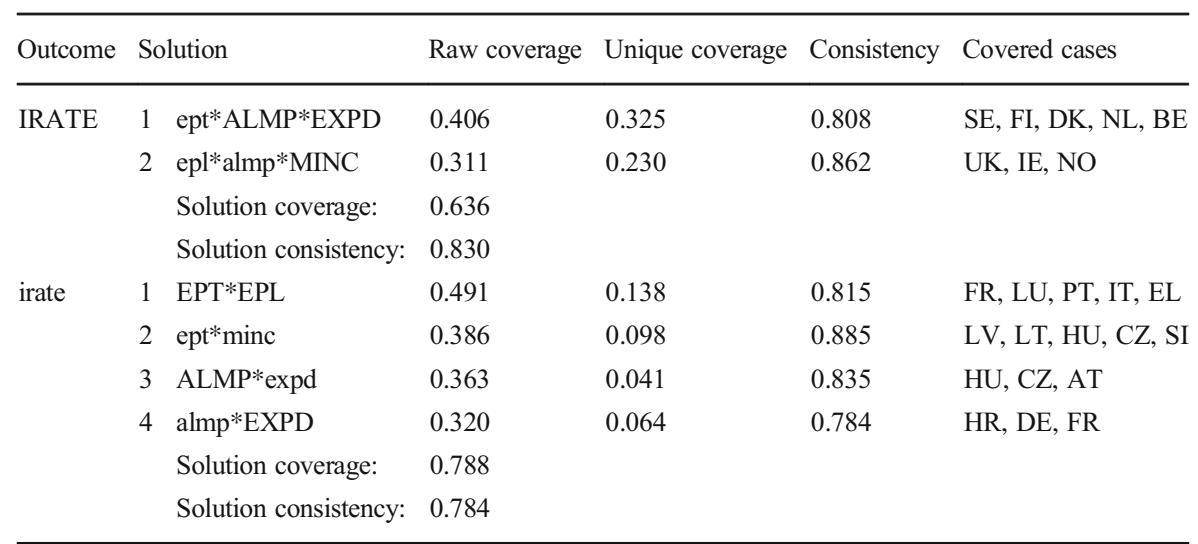

Source: own calculations. Conditions included: EPL, EPT, ALMP, EXPD, and MINC. Most parsimonious solution 


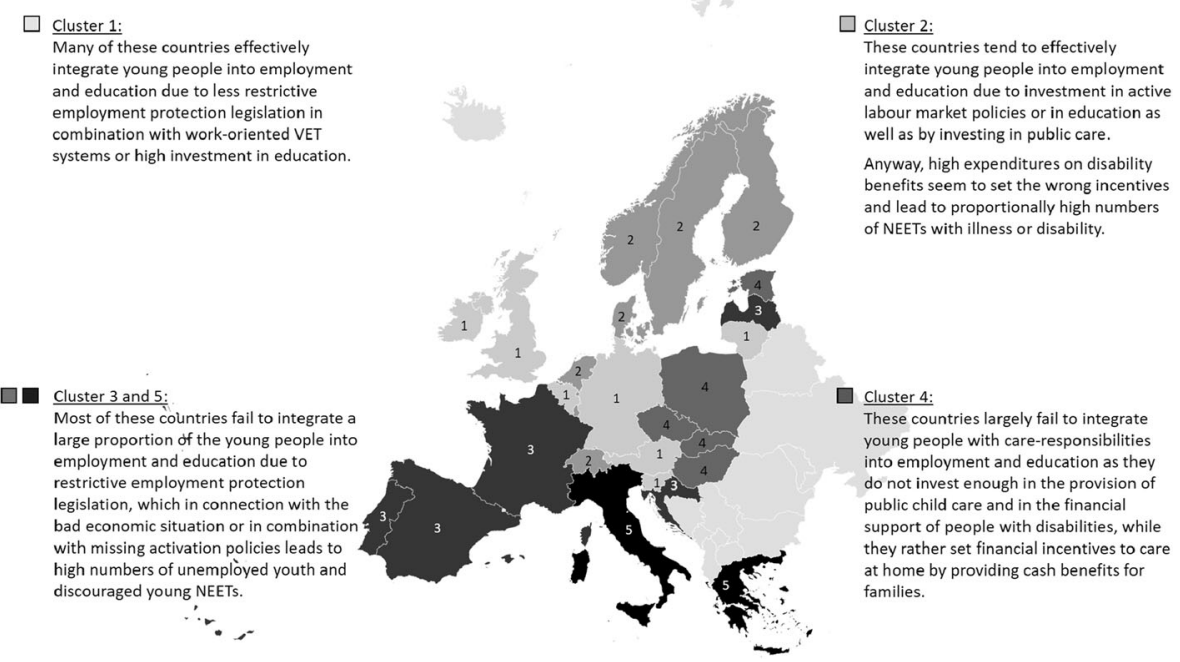

Fig. 3 Summary of country cluster and institutional configurations

in these countries young people with a disability are marginalised and placed in minimum income schemes where they remain instead of being (re-)activated.

The solution for low disability rates contains four configurations. However, the most important configuration in form of the combination of high employment protection for regular and temporary workers is not quite intuitive. The other three configurations are more plausible, indicating that low minimum income benefits and low employment protection for temporary workers, i.e. low barriers for labour market entrants, as well as high expenditures on active labour market policies and low expenditures on disability are associated with low rates of young NEETs with a disability. Even low expenditures on active labour market policies combined with high expenditures on disability can lead to low rates of NEETs with a disability indicating that it is not only the level but apparently the orientation or design of the disability benefit system that matters. Our results on young NEETs with a disability raise some questions and could be affected by the fact that the term 'disability' is understood very differently across welfare systems, which may influence the probability of a young person being categorised as having or experiencing a disability (Kapteyn et al. 2007).

\section{Conclusion}

The empirical analysis examined cross-national variation in the number of young NEETs across Europe and the role institutional configurations play in it. In a first step, a cluster analysis has shown that the level of different subgroups of NEETs differs significantly across Europe, resulting in five distinct country clusters. These differences are not only due to individual but also to structural and institutional factors. Indeed, the results of the fsQCA revealed that features of the labour market, the education and welfare system, and family policies are found to be sufficient conditions for the presence of specific subgroups of NEETs (see Fig. 3). The assumptions that these 
institutions do not exert their effects alone, but only in combination with other institutions (assumption of conjunctural causation) and that different configurations may lead to the same outcome (assumption of equifinality) have proven true. This strengthens the idea that fsQCA is a suitable approach examining the impact of institutional configurations on a complex phenomenon like NEET rates. In sum, the findings highlight that not all countries face the same challenges regarding the disengagement of young people from work and education. While high unemployment and discouragement of young people are the main challenges in some, restrictions related to care-giving responsibilities or disabilities are dominant in others. Therefore, focusing only on labour market policies would ignore the different barriers young people face. On the contrary, country-specific measures must be taken to reduce the number of young NEETs in Europe. Moreover, due to the complex interplay of institutions, holistic approaches are necessary, in the sense that certain policies must be combined with each other and it needs to be avoided that policies counteract each other.

In line with other research (e.g. Eichhorst and Neder 2014; Scarpetta et al. 2010), our findings suggest that the quality and vocational orientation of the educational system as well as a stronger focus on activation measures may play an important role in combating the particularly high NEET rates in Italy and Greece (cluster 5). As the NEETs in these countries are mainly composed of unemployed and discouraged NEETs, investments in education and active labour market policy may have positive impacts on their labour market integration and educational enrolment. This is of course extremely difficult to implement against the background of low economic growth and high levels of public debt and it shows that austerity and the reduction of high NEET rates are mutually exclusive. Another approach would be to examine to what extent labour market regulations - in particular the use of temporary contracts - can be relaxed in these countries to lower the hurdles for employers and give young people a chance. With respect to discouraged NEETs, the positive effect of less restrictive employment protection legislation on the chances of finding a job at all seems to outweigh the negative effect of lower job security. This also applies to the countries of the Southern and Western European cluster such as Spain, Portugal, France, and Croatia (cluster 3). Anyway, our analysis shows that such relaxation of employment protection works best in combination with the investments in education and active labour market policies described above. In addition, our results suggest that structural or institutional factors in the countries have a decisive influence on the assessment of the discouraged NEETs of their labour market chances. In this sense, these young people not only seem to be 'discouraged', but also 'disengaged' from the support of public institutions such as for example public employment offices. This assumption is also supported by the fact that countries that invest particularly high sums in institutions relevant for young people in the transition between school and work, in the form of spending on education and active labour market policies, such as the Western and Central European countries (cluster 1) and the Northern European countries (cluster 2), on the other hand, show particularly low rates of discouraged and unemployed NEETs. Furthermore, we illustrated that welfare and family institutions, which have been widely neglected so far in the NEETs literature, are significant for the prevalence of young NEETs. Especially in the Central Eastern European countries with very high rates of care-giving NEETs (cluster 4), cash benefits for families in combination with missing formal care seem more likely to provide incentives for childcare at home and to 
work against the labour market integration of women. Here, the provision of comprehensive and affordable childcare and other family-related services in addition to formalised long-term care for sick and elderly people may be important preconditions for reducing NEET rates. In contrast, in the Northern European countries, where the number of care-giving NEETs is particularly low, public institutions already provide comprehensive care for children and the elderly (cluster 2). At the same time, in Northern Europe young NEETs with an incapacity or disability are a relevant NEET group in conjunction with high and seemingly inefficient disability benefit schemes. It needs to be ensured that benefits are designed to provide a good livelihood without creating incentives to remain in them forever. The well-developed activation policies in these countries must try to better reach and support this group of young people - the latter is also true for Ireland and the UK.

Our analysis is far from exhaustive and raises further questions. It points to the need for future in-depth research on the specific barriers to education and employment that inactive young NEETs face and especially on the subgroups of NEETs with a disability and discouraged young NEETs Due to the macro-level orientation of the fsQCA, compositional differences in socio-demographics across countries could not be considered which might contribute to differences in NEET rates. Furthermore, other important institutions may have been neglected due to the restrictions regarding the number of conditions included which might lead to spurious relations. This points to the limits of the chosen analytical approach. Anyway, our findings may offer a first step by highlighting the importance of institutional configurations for the extent of young NEETs in Europe, providing policymakers with a better understanding of the specific situation and problems that young people face in their countries.

Supplementary Information The online version contains supplementary material available at https://doi.org/ 10.1007/s43151-021-00040-w.

Acknowledgements We would like to thank Katharina Zimmermann, Jennifer Turner, Martin Heidenreich, and Jenny Preunkert for their valuable support as well as the three anonymous reviewers for their comments and helpful suggestions.

Funding Open Access funding enabled and organized by Projekt DEAL.

\section{Declarations}

Conflict of interest The authors declare no competing interests.

\footnotetext{
Open Access This article is licensed under a Creative Commons Attribution 4.0 International License, which permits use, sharing, adaptation, distribution and reproduction in any medium or format, as long as you give appropriate credit to the original author(s) and the source, provide a link to the Creative Commons licence, and indicate if changes were made. The images or other third party material in this article are included in the article's Creative Commons licence, unless indicated otherwise in a credit line to the material. If material is not included in the article's Creative Commons licence and your intended use is not permitted by statutory regulation or exceeds the permitted use, you will need to obtain permission directly from the copyright holder. To view a copy of this licence, visit http://creativecommons.org/licenses/by/4.0/.
} 
Open Access This article is licensed under a Creative Commons Attribution 4.0 International License, which permits use, sharing, adaptation, distribution and reproduction in any medium or format, as long as you give appropriate credit to the original author(s) and the source, provide a link to the Creative Commons licence, and indicate if changes were made. The images or other third party material in this article are included in the article's Creative Commons licence, unless indicated otherwise in a credit line to the material. If material is not included in the article's Creative Commons licence and your intended use is not permitted by statutory regulation or exceeds the permitted use, you will need to obtain permission directly from the copyright holder. To view a copy of this licence, visit http://creativecommons.org/licenses/by/4.0/.

\section{References}

Bambra C (2007) Defamilisation and welfare state regimes: a cluster analysis. Int J Soc Welf 16:326-338. https://doi.org/10.1111/j.1468-2397.2007.00486.x

Baumgartner M, Thiem A (2017) Model Ambiguities in Configurational Comparative Research. Sociological Methods \& Research 46:954-987. https://doi.org/10.1177/0049124115610351

Baumgartner M, Thiem A (2020) Often Trusted but Never (Properly) Tested: Evaluating Qualitative Comparative Analysis. Sociol Methods Res 49:279-311. https://doi.org/10.1177/0049124117701487

Bell DNF, Blanchflower DG (2010) Youth Unemployment: Déjà Vu? IZA Discussion Paper No. 4705, Bonn

Bol T, van de Werfhorst HG (2013) Educational Systems and the Trade-Off between Labor Market Allocation and Equality of Educational Opportunity. Comp Educ Rev 57:285-308. https://doi.org/10.1086/ 669122

Breen R (2005) Explaining Cross-national Variation in Youth Unemployment. Eur Sociol Rev 21:125-134. https://doi.org/10.1093/esr/jci008

Brzinsky-Fay C (2017) The interplay of educational and labour market institutions and links to relative youth unemployment. J Eur Soc Policy 27:346-359. https://doi.org/10.1177/0958928717719198

Bynner J, Parsons S (2002) Social Exclusion and the Transition from School to Work: The Case of Young People Not in Education, Employment, or Training (NEET). J Vocat Behav 60:289-309. https://doi.org/ 10.1006/jvbe. 2001.1868

Carcillo S, Fernández R, Königs S, Minea A (2015) NEET Youth in the Aftermath of the Crisis: Chal- lenges and Policies. OECD Social, Employment and Migration Working Papers, No. 164, OECD Publishing.

Caroleo FE, Rocca A, Mazzocchi P, Quintano C (2020) Being NEET in Europe Before and After the Economic Crisis: An Analysis of the Micro and Macro Determinants. Soc Indic Res 97:1017-1024. https:// doi.org/10.1007/s11205-020-02270-6

Cavalca G (2016) Young people in transitions : Conditions, indicators and policy implications. To NEET or not to NEET? In: Coppola G, O'Higgins N (eds) Youth and the crisis: Unemployment, education and health in Europe. Routledge, London, pp 272-287

Contini D, Filandri M, Pacelli L (2019) Persistency in the NEET state: a longitudinal analysis. J Youth Stud 22:959-980. https://doi.org/10.1080/13676261.2018.1562161

de Lange M, Gesthuizen M, Wolbers MHJ (2014) Youth Labour Market Integration Across Europe. Eur Soc 16:194-212. https://doi.org/10.1080/14616696.2013.821621

Dietrich H (2013) Youth unemployment in the period 2001-2010 and the European crisis - looking at the empirical evidence. Transfer: European Review of Labour and Research 19:305-324. https://doi.org/10. $1177 / 1024258913495147$

Dietrich H, Möller J (2016) Youth unemployment in Europe - business cycle and institutional effects. Int Econ Econ Policy 13:5-25. https://doi.org/10.1007/s10368-015-0331-1

Dixon J, Hyde M (2000) A Global Perspective on Social Security Programmes for Disabled People. Disability \& Society 15:709-730. https://doi.org/10.1080/713662002

Eichhorst W, Neder F (2014) Youth Unemployment in Mediterranean Countries. IZA Policy Paper No. 80, Bonn

Eurofound (2012) NEETs, young people not in employment, education or training: Characteristics, costs and policy responses in Europe, Luxembourg. https://www.eurofound.europa.eu/sites/default/files/ef_ publication/field_ef_document/ef1254en.pdf

Eurofound (2016) Exploring the Diversity of NEETs, Luxembourg. https://digitalcommons.ilr.cornell.edu/intl/ 594

Eurofound (2017) Reactivate: Employment Opportunities for Economically Inactive People, Luxembourg. https://igitalcommons.ilr.cornell.edu/intl/630 
Eurostat (2017) EU Labour Force Survey Database: User Guide, Brussels

Eurostat (2020) Young people neither in employment nor in education and training (NEET): Statistics Explained. https:/ec.europa.eu/eurostat/statistics-explained/index.php?title=Glossary:NEET. Accessed 26 June 2020

Flaim PO (1973) Discouraged workers and changes in unemployment. Monthly Labor Review 96:8-16

Furlong A (2006) Not a very NEET solution: representing problematic labour market transitions among early school-leavers. Work Employ Soc 20:553-569. https://doi.org/10.1177/0950017006067001

Gangl M (2001) European patterns of labour market entry. A dichotomy of occupationalized vs. nonoccupationalized systems? Eur Soc 3:471-494. https://doi.org/10.1080/14616690120112226

Gangl M (2006) Scar Effects of Unemployment: An Assessment of Institutional Complementarities. Am Sociol Rev 71:986-1013. https://doi.org/10.1177/000312240607100606

Gebel M, Giesecke J (2016) Does Deregulation Help? The Impact of Employment Protection Reforms on Youths' Unemployment and Temporary Employment Risks in Europe. Eur Sociol Rev 32:486-500

Gray J, Jesson D, Sime N (1992) The 'Discouraged Worker' Revisited: Post-16 Participation in Educa- tion South of the Border. Sociology 26:493-505. https://doi.org/10.1177/0038038592026003008

Gregg P, Tominey E (2005) The wage scar from male youth unemployment. Labour Econ 12:487-509. https://doi.org/10.1016/j.labeco.2005.05.004

Hall PA, Soskice DW (2001) Varieties of capitalism: The institutional foundations of comparative advantage. Oxford University Press, Oxford England, New York

Hudson J (2017) Youth Labor Market Conditions and the NEET Population in the EU: Do Poor Labor Market Opportunities Discourage Youth? Electronic Theses and Dissertations:2004-2019

ILO (2015) What does NEETs mean and why is the concept so easily misinterpreted?: Technical Brief No.1, Geneva

Kapteyn A, Smith JP, van Soest A (2007) Vignettes and Self-Reports of Work Disability in the United States and the Netherlands. Am Econ Rev 97:461-473. https://doi.org/10.1257/aer.97.1.461

Korpi T, Levin H (2001) Precarious Footing: Temporary Employment as a Stepping Stone out of Unemployment in Sweden. Work Employ Soc 15:127-148. https://doi.org/10.1017/S095001700100006X

de Luca G, Mazzocchi P, Quintano C, Rocca A (2020) Going Behind the High Rates of NEETs in Italy and Spain: The Role of Early School Leavers. Soc Indic Res 151:345-363. https://doi.org/10.1007/s11205020-02370-3

Marques P, Hörisch F (2020) Understanding massive youth unemployment during the EU sovereign debt crisis: a configurational study. Comp Eur Polit 18:233-255. https://doi.org/10.1057/s41295-019-00184-3

Marx A (2006) Towards more robust model specification in QCA resulting from a methodological experiment. COMPASSS - Working Paper, Antwerp

Marx A, Rihoux B, Ragin C (2014) The origins, development, and application of Qualitative Compara- tive Analysis: the first 25 years. Eur Polit Sci Rev 6:115-142. https://doi.org/10.1017/S1755773912000318

Mascherini M (2019) Origins and future of the concept of NEETs in the European policy agenda. In: O'Reilly J, Leschke J, Ortlieb R, Seeleib-Kaiser M, Villa P (eds) Youth labor in transition: Inequali- ties, mobility, and policies in Europe. Oxford University Press, New York, NY, United States of America, pp 503-529

Michoń P (2008) Familisation and defamilisation policy in 22 European countries. The Poznań Univer-sity of Economics Review 8:34-54

Noelke C (2016) Employment Protection Legislation and the Youth Labour Market. Eur Sociol Rev 32:471485. https://doi.org/10.1093/esr/jcv088

OECD (2008) Sickness, Disability and Work: Breaking the Barriers (Vol. 3): Denmark, Finland, Ireland and the Netherlands, Paris

OECD (2013) Drivers of Female Labour Force Participation in the OECD. OECD Social. Employment and Migration Working Papers No. 145, Paris

OECD (2016) The NEET challenge: What can be done for jobless and disengaged youth? Society at a Glance, Paris

Pemberton S (2008) Tackling the NEET Generation and the Ability of Policy to Generate a 'NEET' Solution-Evidence from the UK. Environ Plann C Gov Policy 26:243-259. https://doi.org/10.1068/c0654

Raffe D, Willms JD (1989) Schooling the Discouraged Worker: Local-Labour-Market Effects on Educational Participation. Sociology 23:559-581. https://doi.org/10.1177/0038038589023004004

Ragin CC (2000) Fuzzy-set social science. Univ. of Chicago Press, Chicago

Ragin CC (2006) Set Relations in Social Research: Evaluating Their Consistency and Coverage. Polit Anal $14: 291-310$

Ragin CC (2008a) Redesigning social inquiry: Fuzzy sets and beyond, [Nachdr.]. Univ. of Chicago Press, Chicago, Ill 
Ragin CC (2008b) The comparative method: Moving beyond qualitative and quantitative strategies. Univ. of California Press, Berkeley, Calif

Ragin CC, Davey S (2016) Fuzzy-Set/Qualitative Comparative Analysis 3.0, Irvine, California: Depart- ment of Sociology, University of California

Robson K (2008) Becoming NEET in Europe: A comparison of predictors and later-life outcomes. Paper presented at the Global Network on Inequality Mini-Conference on February 22, 2008 in New York City

Russell H, O'Connell PJ (2001) Getting a Job in Europe: The Transition from Unemployment to Work among Young People in Nine European Countries. Work Employ Soc 15:1-24. https://doi.org/10.1017/ S0950017001000010

Ryan P (2001) The School-to-Work Transition: A Cross-National Perspective. J Econ Lit 39:34-92

Samoilenko A, Carter K (2015) Economic outcomes of youth not in education, employment or training (NEET). New Zealand Treasury working paper, Wellington

Scarpetta S, Sonnet A, Manfredi T (2010) Rising Youth Unemployment During The Crisis: How to Prevent Negative Long-Term Consequences on a Generation. OECD Social, Employment and Migration Working Papers No. 106, Paris

Schneider CQ, Wagemann C (2010) Standards of Good Practice in Qualitative Comparative Analysis (QCA) and Fuzzy-Sets. Comp Sociol 9:397-418. https://doi.org/10.1163/156913210X12493538729793

Schneider CQ, Wagemann C (2012) Set-Theoretic Methods for the Social Sciences: A Guide to Quali- tative Comparative Analysis. In: Strategies for social inquiry. Cambridge Univiversity Press, Cam- brigde

Schweitzer SO, Smith RE (1974) The Persistence of the Discouraged Worker Effect. ILR Rev 27:249-260. https://doi.org/10.1177/001979397402700207

Shavit Y, Müller W (2000) Vocational secondary education.: Where diversion and where safety net? Eur Soc 2:29-50

Skedinger P (2010) Employment protection legislation: Evolution, effects, winners and losers. Edward Elgar Pub, Cheltenham, U.K

Spasova S, Baeten R, Coster S, Ghailani D, Peña-Casas R, Vanhercke B (2018) Challenges in long-term care in Europe. A study of national policies 2018, Brussels

Stanwick J, Forrest C, Skujins P (2017) Who Are the Persistently NEET Young People? Literature Overview Support Document. https://eric.ed.gov/?id=ed577565

Thévenon O (2013) Drivers of Female LabourForce Participation in the OECD. OECD Social, Employment and Migration Working Papers, Paris https://www.oecd-ilibrary.org/social-issues-migration-health/ drivers-of-female-labour-force-participation-in-the-oecd_5k46cvrgnms6-en

Thiem A (2017) Conducting Configurational Comparative Research With Qualitative Comparative Analysis: A Hands-On Tutorial for Applied Evaluation Scholars and Practitioners. Am J Eval 38:420-433. https:// doi.org/10.1177/1098214016673902

Thiem A (2019) Beyond the Facts: Limited Empirical Diversity and Causal Inference in Qualitative Comparative Analysis. Sociol Methods Res:004912411988246. https://doi.org/10.1177/ 0049124119882463

van Ham M, Mulder CH, Hooimeijer P (2001) Local Underemployment and the Discouraged Worker Effect. Urban Stud 38:1733-1751. https://doi.org/10.1080/00420980120084831

Vancea M, Utzet M (2018) School-to-work transition: the case of Spanish NEETs. J Youth Stud 21:869-887. https://doi.org/10.1080/13676261.2017.1421313

WHO (2011) World report on disability. WHO, Geneva

Wolbers MHJ (2007) Patterns of Labour Market Entry. Acta Sociologica 50:189-210. https://oi.org/10.1177/ 0001699307080924

Yates S, Payne M (2006) Not so NEET? A Critique of the Use of 'NEET' in Setting Targets for Interven- tions with Young People. J Youth Stud 9:329-344. https://doi.org/10.1080/13676260600805671 